
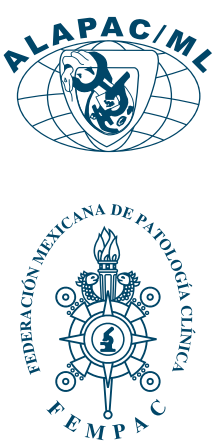

Palabras clave:

Gastroenteritis

infecciosa, PCR

múltiplex, diagnóstico

molecular.

Keywords:

Infectious

gastroenteritis,

multiplex PCR,

molecular diagnosis.

* Médico residente del tercer año en la Especialización en Patología Clínica. ‡ Infectólogo Pediatra adscrito al Servicio de Pediatría.

$\S$ Jefa de Laboratorio Clínico.

Centro Médico ABC.

Correspondencia: Jesús Hernández Ramírez

Laboratorio de Patología Clínica, Centro Médico ABC, Campus Observatorio. Sur 138, Núm. 116, Las Américas, 01120. Alcaldía Álvaro Obregón, Ciudad de México, CDMX Tel: 55 3645-2084 E-mail: jhernandezr@ abchospital.com

Recibido:

20/08/2020

Aceptado:

06/10/2020

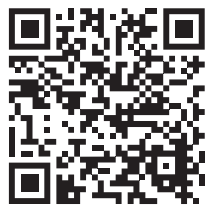

\title{
Impacto de una PCR múltiplex en el diagnóstico y tratamiento en pacientes con gastroenteritis infecciosa
}

\author{
Impact of a multiplex PCR on the diagnosis and treatment \\ of patients with acute infectious gastroenteritis
}

Hernández Ramírez Jesús,* Morales Aguirre C, ${ }^{\ddagger}$ Núñez Martínez M\$

RESUMEN

La gastroenteritis infecciosa (GEPI) continúa siendo un problema de salud pública; causa más de cinco millones de casos de diarrea de origen infeccioso, alto costo económico y de vidas humanas. El diagnóstico tradicionalmente emplea métodos microbiológicos e inmunológicos, con resultados de horas a días. Las pruebas de reacciones de la polimerasa en cadena (PCR) múltiplex permiten analizar más de 20 patógenos en menos tiempo. Objetivos: Identificar el agente causal, diagnóstico y tratamiento específico, uso inadecuado de antibióticos, reducir complicaciones, estancia hospitalaria, recursos inadecuados, aportar datos epidemiológicos, educación y prevención de salud. Material y métodos: Estudio retrospectivo, observacional y analítico. Un total de 150 pacientes con diagnóstico clínico de GEPI, estudios convencionales de laboratorio y PCR múltiplex, variables demográficas, historia clínica, antibiótico empírico, cambios en manejo médico, estancia hospitalaria, complicaciones y agentes infecciosos. Resultados: $64 \%$ fueron positivos para una prueba convencional; $83 \%$ fueron adultos y $17 \%$ niños, relación $1: 1$ entre hombres y mujeres; edad mínima de un mes y máxima de 93 años. El sedentarismo, adultos mayores de 65 años, estancia prolongada en hospital y la inmunosupresión como comorbilidades con $67 \%$. Al $73 \%$ se les indicó un estudio convencional al ingreso. Diagnóstico presuntivo de GEPI en $58 \%$; inicio de tratamiento empírico en $72 \%$. La prueba molecular PCR múltiplex fue positiva para $76 \%$, con reporte de uno hasta seis agentes; escalamiento farmacológico en $25 \%$ y desescalamiento en 33\%, 37\% no recibió tratamiento o fue suspendido. La estancia intrahospitalaria de 1.02 días en promedio. Recuperación de pacientes de $99 \%$ y la implementación de medidas preventivas fue de $69 \%$. Conclusiones: El panel PCR múltiplex mostró un alto rendimiento diagnóstico, mejores detalles del espectro de patógenos. Con su uso y aplicación adecuada apoyó a la disminución de la estancia intrahospitalaria, complicaciones, uso inadecuado de terapias antimicrobianas, educación y prevención de salud.

\section{ABSTRACT}

Acute infectious gastroenteritis continues to be a public health problem, causing more than five million cases of diarrhea of infectious origin, with a high economic cost and human lives. Diagnosis traditionally employs microbiological and immunological methods with results from hours to days; multiplex PCR tests allow to analyze more than 20 pathogens in less time. Objective: Identification of the causative agent, diagnosis and specific treatment, inappropriate use of antibiotics, reduce complications, hospital stay, inadequate resources, provide epidemiological data, education and health prevention. Material and methods: Retrospective, observational and analytical study. A total of 150 patients with a clinical diagnosis acute infectious gastroenteritis, conventional laboratory studies and multiplex PCR, demographic variables, clinical history, empirical antibiotics, changes in medical management, hospital stay, complications, and infectious agents. Results: $64 \%$ were positive for a conventional test; $83 \%$ were adults and $17 \%$ children, a 1:1 ratio between men and women; minimum age of one month and maximum of 93 years. Sedentary lifestyle, adults over 65 years of age, prolonged hospital stay, and immunosuppression as comorbidities with $67 \% .73 \%$ were given a conventional study upon admission. Presumptive diagnosis in $58 \%$; initiation of empirical treatment in $72 \%$. The multiplex PCR molecular test was positive for $76 \%$ with reports of one to six agents; pharmacological escalation in $25 \%$ and de-escalation in $33 \%, 37 \%$ who received no treatment or were suspended. Average hospital stay of 1.02 days. Recovery of $99 \%$ of patients and the implementation of preventive measures was 69\%. Conclusions: The multiplex PCR panel showed high diagnostic performance, better details of the pathogen spectrum. With its use and proper application, it supported the reduction of hospital stay, complications, inappropriate use of antimicrobial therapies, education and health prevention.

Citar como: Hernández RJ, Morales AC, Núñez MM. Impacto de una PCR múltiplex en el diagnóstico y tratamiento en pacientes con gastroenteritis infecciosa. Rev Mex Patol Clin Med Lab. 2020; 67 (3): 129-141. https://dx.doi.org/10.35366/96676 


\section{INTRODUCCIÓN}

a gastroenteritis de origen infeccioso es la disfun—ción y la inflamación intestinal provocada por un microorganismo de origen bacteriano, viral y parasitario o sus toxinas. Cursa con diarrea, acompañada o no de fiebre, vómitos y dolor abdominal. Representa una causa importante de morbilidad mundial y una de las primeras de mortalidad en los países en vías de desarrollo. ${ }^{1}$

En el pasado, la deshidratación grave y la pérdida de líquidos eran las principales causas de muerte por diarrea. En la actualidad, es probable que otras causas, como las infecciones bacterianas septicémicas, sean responsables de una proporción cada vez mayor de muertes relacionadas con la diarrea. Los pacientes malnutridos o inmunodeprimidos son los que presentan mayor riesgo de enfermedades diarreicas potencialmente mortales. ${ }^{2}$

Debido a la transición epidemiológica en México antes de 1980, las principales causas de mortalidad eran infectocontagiosas. Sin embargo, a pesar de que las enfermedades diarreicas agudas (EDAS) poseen una tendencia secular descendente, las que han disminuido en 55.7\% de 1988 a 2011, para este último año aparecen todavía dentro de las 20 principales causas de mortalidad general en nuestro país, ocupan el lugar 18 y la mayor parte de las defunciones por este padecimiento. ${ }^{3}$

Se reportan para el año 2014, de acuerdo con las guías de práctica clínica y la Secretaría de Salud, más de cinco millones y medio de casos de diarrea de origen infeccioso. En 2017, según datos del INEGI, de los 569 decesos por enfermedades diarreicas agudas en menores de cinco años, la causa principal de muerte fue la clasificada como diarrea y gastroenteritis de presunto origen infeccioso, ya que representó 96.3\% (548 casos). Como segunda causa, aparecen las infecciones intestinales debidas a microorganismos especificados con sólo 1.4\% (ocho casos). ${ }^{4}$

\section{MANIFESTACIONES CLÍNICAS DE LA ENFERMEDAD}

Su duración es inferior a 14 días si su inicio es agudo, pero si se mantiene de dos a cuatro semanas, se denomina diarrea persistente. Suele ir acompañada de otros síntomas como náuseas, vómitos, dolor abdominal e incluso fiebre, esta última puede entenderse como una respuesta protectora frente a agresiones intestinales.

Por su origen, podemos clasificarla en dos rubros: infecciosa, que constituye $80 \%$ de los casos de diarrea aguda y su forma de adquisición más habitual es el contagio de persona a persona o por la ingesta de alimentos y agua contaminada. No infecciosa, que puede venir provocada por distintas causas incluyendo fármacos, alergia o intolerancia a los alimentos, estrés psicológico y patologías crónicas. ${ }^{5}$

\section{CRITERIOS DIAGNÓSTICOS}

Cuando el paciente que acude a la consulta médica presenta síntomas evidentes, no suele ser necesario realizar alguna exploración para confirmar un diagnóstico de diarrea, aunque siempre se debe intentar determinar su causa. Se debe tener en cuenta la historia clínica para valorar si existen elementos que predispongan a una determinada etiología o si hay factores de riesgo que puedan agravar el cuadro. Es importante indagar sobre la posibilidad de que el paciente pertenezca a un grupo de personas con similar sintomatología que pudiera hacer sospechar una intoxicación alimentaria. Además de descartar el origen alimentario, también debe considerarse la posibilidad de que se trate de una reacción adversa a medicamentos.

En pacientes con síntomas moderados o graves, si no se puede constatar el origen, podría ser necesario efectuar pruebas complementarias para confirmar la etiología y seleccionar el tratamiento. Se suelen realizar, entre otras, análisis de sangre, heces y en pacientes con tratamiento reciente de antibiótico, la prueba de detección de toxina de Clostridium difficile. ${ }^{6}$

\section{COMORBILIDAD ASOCIADA}

Principalmente, malnutrición, que abarca carencias o excesos, lo que provoca desequilibrio de la ingesta de energía y nutrientes en una persona, malos hábitos de higiene, estancia prolongada en hospitales, guarderías, asilos, prisiones y nivel socioeconómico. Afecta en especial a los extremos de la vida, causando de manera inicial ausentismo laboral y escolar, diversos grados de deshidratación, insuficiencia renal aguda, sepsis, daño orgánico múltiple y muerte. ${ }^{7}$

Las infecciones gastrointestinales pueden ser causadas por una amplia gama de patógenos como: bacterias, virus, parásitos, y con menor frecuencia hongos.

De acuerdo a la región, las condiciones higiénicas y culturales de cada lugar, se estima que en general hasta $80 \%$ son de etiología viral, $10-20 \%$ bacterianas y cerca de $5 \%$ parasitarias. En cuanto a la transmisión, $80 \%$ de éstas en países desarrollados, se deben a alimentos. El contagio persona a persona se produce en especial en patógenos que requieren una pequeña cantidad de inoculo para producir infección. ${ }^{8}$ 


\section{FISIOPATOLOGÍA DE LA ENFERMEDAD}

Se desarrolla en torno al comportamiento del agente causal directamente con el enterocito. Entender las características particulares de cada patógeno representa diversos mecanismos y tipos de diarreas, ya sea por modificación de la superficie de absorción, invasión de la célula entérica o la producción de toxinas con posterior destrucción del mismo. La diarrea aparece cuando el volumen de agua y electrolitos presente en la luz intestinal supera la capacidad de absorción del colon, con la consecuente eliminación aumentada por las heces. Esto ocurre fundamentalmente por dos motivos: un aumento de la secreción y una disminución de la absorción. Los patógenos ocasionan daño en la mucosa intestinal, ya sea de manera directa, con invasión o a través de toxinas. De cualquiera de las dos formas se produce un daño físico y funcional en los mecanismos de absorción de agua y electrolitos de la mucosa intestinal, una estimulación de la eliminación de los mismos y un daño en las hidrolasas presentes en la mucosa, con la posible malabsorción de lactosa y otros nutrientes, lo que favorece la deshidratación y la desnutrición. ${ }^{9}$

La reacción febril suele presentarse como resultado de la exposición del cuerpo a microorganismos infectantes, complejos inmunitarios u otras causas de inflamación. Esta reacción se inicia por los efectos de agentes inductores externos como bacterias o por toxinas, los cuales estimulan la producción de pirógenos endógenos, ya sea mediadores solubles o citoquinas, células de la línea monocito macrofágica, linfocitos o células infectadas por virus y otras. Entre las citoquinas circulantes con acción pirogénica se encuentran la interleuquina 1 a y $\beta$, la interleuquina 6 , el factor de necrosis tumoral $\alpha$ y $\beta$, el interferón $\alpha$ y $\beta$ y la proteína a inflamatoria del macrófago.

Las prostaglandinas E2 se difunden atravesando la barrera hematoencefálica hasta el área preóptica del hipotálamo anterior, producen la liberación de citoquinas en los sitios terminales y distales de las neuronas responsables de los componentes autonómicos, endocrinos y conductuales de la respuesta febril. La fiebre aparece cuando hay un ajuste en la elevación transitoria del punto prefijado del centro termosensible. Cuando esto se produce, la temperatura corporal resultará aumentada con respecto al valor de referencia y, consecuentemente, se desarrollan mecanismos, cuya resultante funcional es la pérdida de calor, principalmente a través de la vasodilatación y sudoración que tienden a revertir la temperatura del organismo a un valor comprendido en el rango de la normalidad. ${ }^{10}$

\section{PRONÓSTICO}

La fiebre por encima de $38{ }^{\circ} \mathrm{C}$, la aparición de sangre en las heces, dolor abdominal intenso y los signos de afectación del sistema nervioso central como irritabilidad, decaimiento y convulsiones son signos de alerta para aparición de deshidratación grave. Según la Organización Mundial de la Salud se deberían establecer tres grupos en deshidratación: leve o mínima con menos de 3\% de pérdida de peso corporal, deshidratación moderada 3-9\% y grave con más de $10 \%{ }^{11}$

Como sólo es posible comprobar la pérdida de peso en una minoría de los casos, se debe intentar estimar el grado de deshidratación a través de los datos recogidos en la anamnesis y los signos de la exploración física. Se debe preguntar por el número, frecuencia, consistencia y volumen de las deposiciones; si hay vómitos, ingesta de líquidos y nutrientes, la diuresis, la actividad física que mantiene el paciente y su estado general. Los distintos estudios demuestran que la fiabilidad de los signos de la exploración no es muy buena a la hora de diagnosticar la deshidratación, y que la mayoría de los médicos suele realizar una sobreestimación. Los datos que son más fiables a la hora de determinar el grado de deshidratación son el relleno capilar, la turgencia de la piel, la existencia de un patrón respiratorio alterado y pruebas básicas de laboratorio como relación nitrógeno ureico en la sangre BUN/creatinina, sodio, potasio y cloro séricos.

Otros signos clínicos que pueden ser valorados son el frío en las extremidades, la ausencia de lágrimas con el llanto o el pulso débil. Las mucosas secas, los ojos hundidos o la fontanela deprimida son menos fiables a la hora del diagnóstico de deshidratación.

Los criterios clínicos para derivar a un paciente al hospital para un posible ingreso son: deshidratación moderada a grave o choque, diarrea inflamatoria grave con apariencia de afectación del estado general, síntomas neurológicos, incapacidad para la rehidratación oral, sospecha de patología quirúrgica abdominal y pacientes de alto riesgo como inmunodeprimidos, enfermedad grave de base y extremos de la vida, es decir, niños menores de cinco años y adultos mayores de 65 años. ${ }^{12}$

La reducción de daño y de las complicaciones es adecuada con un buen plan de hidratación y la identificación del agente causal por diversas metodologías empleadas en laboratorio, además del escalamiento o desescalameinto de terapias antimicrobianas, reducción de días de estancia hospitalaria, que en casos graves en pacientes de alto riesgo, ha demostrado una menor tasa de complicaciones y defunciones, sobre todo en pacientes inmunodeprimidos. ${ }^{13}$ 


\section{RESPUESTA TEMPRANA}

Es imprescindible una valoración médica temprana, así como el reconocimiento de signos y síntomas sugerentes de la enfermedad, implementar medidas higiénicas y de mantenimiento. Sólo en casos recomendados, iniciar antibioticoterapia empírica posterior a la toma de muestra de heces para análisis de laboratorio.

La prueba de coprocultivo se debe realizar dentro de las primeras 24 horas de los síntomas y es útil para la identificación del agente causal de diarrea de origen bacteriano, principalmente Escherichia coli, Salmonella, Shigella, Campylobacter y Vibrio cholerae. El coprocultivo tarda de 24 a 72 horas, según el germen.

El análisis coprológico busca alteraciones físicoquímicas de las heces y una identificación rápida de microorganismos con la observación microscópica directa, su emisión de resultados es de dos a seis horas.

El examen coproparasitoscópico es el método utilizado para la detección e identificación de parásitos en materia fecal y tejidos del tubo digestivo, se recomienda realizar dentro de las primeras 24 horas de los síntomas y su tiempo de emisión de resultados varía entre ocho y 24 horas; consta de diversas metodologías para la búsqueda de protozoarios, quistes, huevecillos, uncinarias, tremátodos, nemátodos y céstodos.

Las técnicas inmunológicas de Rota-test y la detección de toxina de Clostridium difficile se recomiendan en casos donde quieran descartarse infecciones secundarias a rotavirus o diarrea secundaria al uso de antibióticos de amplio espectro. ${ }^{14}$

Las técnicas moleculares detectan actualmente uno o más agentes infecciosos con alta sensibilidad y especificidad. La tasa de detección es generalmente mayor que la de los métodos tradicionales, por lo que es probable detectar dichos agentes de origen bacteriano, parasitario y viral en diferentes fases de la infección: incipiente, aguda o pasada. Se realiza en muestras de materia fecal y se recomienda durante el periodo de las primeras ocho a 24 horas de la infección, con emisión de resultados en dos horas máximo desde su análisis en el laboratorio clínico. ${ }^{15}$

\section{MEDIDAS GENERALES}

Ingesta adecuada de líquidos, con tomas frecuentes y en pequeñas cantidades, además de incluir alimentos blandos y semisólidos. Las primeras 24 horas de la enfermedad es recomendable utilizar líquidos claros y alcalinos $y$, posteriormente, sustituir por preparados de suero oral hasta tolerar vía oral de manera íntegra. Cada vez que exista una deposición, hay que lavar muy bien las manos con agua y jabón. Mientras se encuentre enfermo, es importante no manipular alimentos o estar en contacto con diversos miembros de la familia. El personal clínico debe tener medidas de prevención con el uso adecuado de guantes y lavado de manos antes, durante y después del contacto con el paciente o sus secreciones.

\section{TRATAMIENTO FARMACOLÓGICO}

Desde el punto de vista etiológico, no existe tratamiento para las causas virales. En el caso de las diarreas de tipo bacteriano, de primera instancia los antibióticos no están indicados. La mayor parte de las veces se da tratamiento sintomático, y se mantiene el estado de nutrición e hidratación de los pacientes. ¿Pero en quiénes sí está indicado el uso de antibióticos ante pacientes con cuadros diarreicos? Están indicados: 1) en recién nacidos; 2) en pacientes inmunosuprimidos; 3 ) en pacientes que tienen algún tratamiento o alguna enfermedad crónica que los inmunocomprometa (leucémicos o que están recibiendo esteroides, por ejemplo); 4) en quienes a pesar del tratamiento desde el punto de vista sintomático, persisten con el cuadro enteral activo y no mejoran; 5) en los que se vean sépticos o toxiinfectados; y 6 ) en aquellas diarreas de carácter mucosanguinolento, donde está plenamente justificado el inicio de antibióticos. ${ }^{16}$

Para diarrea no inflamatoria, los agentes causales más comunes son los rotavirus y virus entéricos, astrovirus, sapovirus, calicivirus; bacterias como Staphylococcus aureus y parásitos como Giardia lamblia.

Para diarrea inflamatoria existe comúnmente alta relación con Salmonella sp, Shigella, Escherichia coli, Campylobacter, Yersinia y Clostridium.

Finalmente, para toxiinfección alimentaria comúnmente Salmonella sp, Campylobacter, Escherichia coli, Shigella, Staphylococcus aureus, virus Norwalk, rotavirus y Vibrio sp.

Para diarrea no inflamatoria la antibioticoterapia empírica no está indicada, a excepción de la sospecha de cólera grave con el uso de azitromicina o alternativa doxiciclina, tetraciclina y ciprofloxacino.

En diarrea inflamatoria, la antibioticoterapia empírica para los agentes causales abarca eritromicina, azitromicina, ampicilina, ceftriaxona, cefotaxima, ciprofloxacino y norfloxacino.

La diarrea generada por toxiinfección el tratamiento antibiótico abarca ampicilina, eritromicina, azitromicina, cefotaxima y ceftriaxona.

En casos especiales de diarrea asociada a antibióticos es importante retirar antibiótico previo y usar metronidazol o, como alternativa, vancomicina. 
Existen vacunas orales vivas atenuadas para la prevención de la infección grave de origen viral por rotavirus en presentación monovalente. ${ }^{17}$

\section{DESENLACE}

Las principales secuelas que se observan en los pacientes con gastroenteritis infecciosa se deben a las complicaciones por un mal manejo y pobre control de la enfermedad, en individuos con inmunosupresión o un sistema inmunológico deficiente, existe una mayor probabilidad de infección generalizada, falla orgánica, sepsis y muerte temprana. En el resto de la población, la principal complicación es un estado de deshidratación muy importante con secuelas a nivel del sistema nervioso central y la diseminación y descontrol del agente causal en el círculo del paciente. Cuando se logran controlar estos factores, la respuesta es favorable, con alta tendencia a la curación. ${ }^{7}$

A pesar de los grandes esfuerzos para el control de esta enfermedad, la Organización Mundial de la Salud considera que su prevalencia continuará vigente, sobre todo por la adaptación de agentes víricos al medio sin importar el nivel socioeconómico del individuo, por lo que la identificación del agente causal aportaría información muy valiosa para el control de estas enfermedades, epidemiología y su adecuado manejo intra- o extrahospitalario.

\section{Pruebas moleculares PCR múltiplex}

En general, el diagnóstico mediante técnicas de biología molecular ha tenido un fuerte impacto en la detección de patógenos. En el estudio de las infecciones gastrointestinales, estas técnicas han ampliado el número de patógenos detectados, sobre todo con el uso de técnicas de reacciones de la polimerasa en cadena múltiple. Sin embargo, estas técnicas son costosas, requieren de personal entrenado y están limitadas a ciertos patógenos, careciendo además de validaciones y certificaciones que entreguen seguridad al equipo clínico para la indicación del tratamiento adecuado. Recientemente, la Food and Drugs Administration (FDA) ha liberado para su uso en clínica el panel FilmArray $G I^{\circledR}$, que permite, en una sola reacción, la detección de 22 patógenos entéricos: virales Adenovirus F40/41, Astrovirus, Norovirus GI/GII, Rotavirus A, Sapovirus I, II, IV y V; bacterianos Campylobacter spp., Clostridium dificile, Plesiomonas shigelloides, Salmonella spp., Yersinia enterocolítica, Vibrio parahaemolyticus, Vibrio vulnificus, Vibrio cholerae, Shigella spp. Escherichia coli enteroagregativa, E. coli enteropatogénica, E. coli enterotoxigénica, E. coli productora de toxina Shiga y E. coli enteroinvasora; y parasitarios Cryptosporidium,
Cyclospora cayetanensis, Entamoeba histolytica y Giardia lamblia. Esta técnica integra la extracción y purificación de ácidos nucleicos directamente de la muestra y la detección de las regiones génicas amplificadas. El proceso completo de entrega de resultados se realiza en una a dos horas aproximadamente. ${ }^{18}$

Proceso de la muestra. Una muestra biológica de heces, de preferencia con características diarreicas, contenida en un recipiente de boca ancha, limpio sin contaminación ambiental o de orina y recolectada no más de dos horas de su emisión directa, se somete a purificación de ácidos nucleicos, transcripción inversa y una reacción combinada de anidamiento y multiplicación de 50 a 60 ciclos de reacción en cadena de polimerasa, junto con análisis de una curva de fusión del ADN o ARN para detectar y distinguir múltiples patógenos de forma simultánea.

Las reacciones bioquímicas están encerradas en un kit con bolsa desechable, lo que minimiza el riesgo de contaminación y la capacidad de detectar más de 100 dianas de ácido nucleico diferentes a la vez.

Cada kit se compone de un depósito de inyección de polipropileno, con medidas aproximadas de $120 \times$ $10 \times 25 \mathrm{~mm}$ de ancho, largo y alto, el cual se encuentra soldado a dos hojas en una película de poliéster que contiene un polímero con capa adhesiva, posee dos canales que comprenden las estaciones de procesamiento de la muestra y una matriz con 120 pocillos, además de contener 12 depósitos de agua que purificarán la muestra. En los extremos del kit se insertan las ampollas con muestra y diluyente, además de agente a base de tripsina que descompone las uniones proteicas de los ácidos nucleicos (Figura 1). ${ }^{19}$

Técnica empleada para la PCR múltiplex. De manera resumida, se explican los pasos que realiza el equipo de marca Biofire.

1. Purificación del ácido nucleico: ésta tiene lugar en las tres primeras ampollas de la bolsa. La muestra se lisa mediante una combinación de mecanismos químicos y mecánicos (batido de perlas) y el ácido nucleico liberado se captura, lava y eluye mediante la tecnología de perlas magnéticas. Estas etapas requieren aproximadamente 10 minutos, y el ruido del equipo homogeneizador de perlas se percibe como un chirrido agudo durante los primeros minutos de funcionamiento.

2. Transcripción inversa y 1a etapa de la PCR múltiple: puesto que el panel gastrointestinal incluye virus de ARN, se realiza una etapa de transcripción inversa (RT) para convertir el ARN vírico en ADNc antes de la amplificación. La solución de ácido nucleico purifica- 


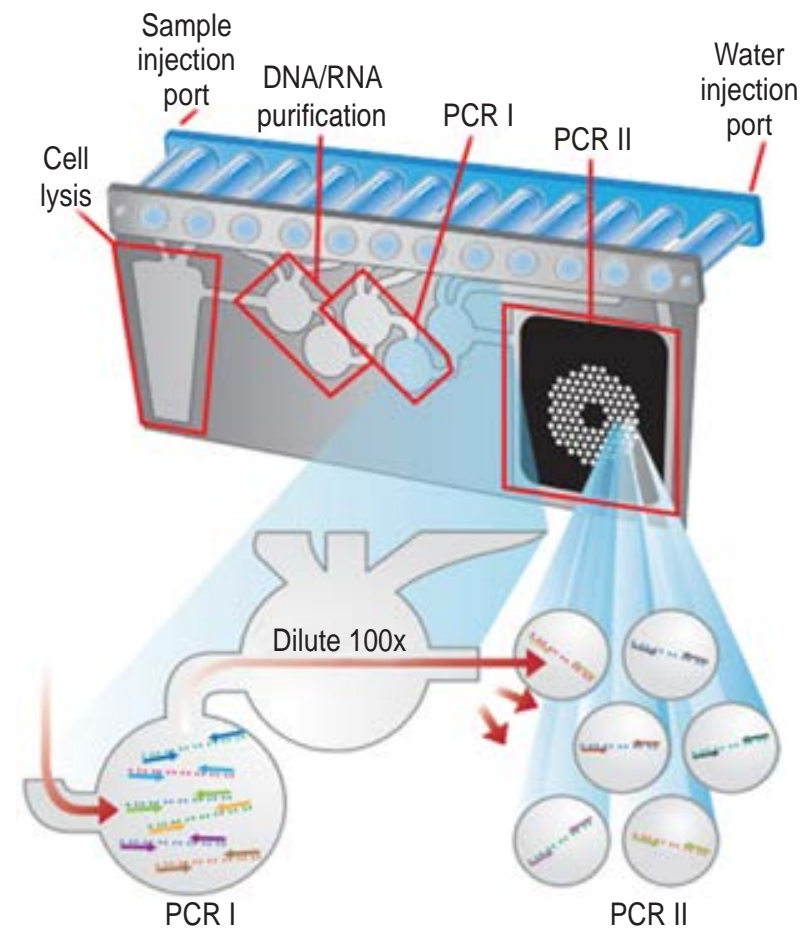

Figura 1: Interior de kit de reacción PCR múltiplex.

da se combina con una mezcla maestra precalentada para iniciar la etapa de RT y el termociclado posterior para la PCR múltiple. El efecto de la primera etapa de la PCR es enriquecer los ácidos nucleicos diana presentes en la muestra.

3. Segunda etapa de la PCR: los productos de la primera etapa de la PCR se diluyen y mezclan con reactivos de PCR nuevos que contienen un colorante intercalador fluorescente del ADN. Esta solución se distribuye en la matriz de la segunda etapa de la PCR. Los depósitos individuales de la matriz contienen los cebadores de los diferentes ensayos (cada uno por triplicado), dirigidos a las secuencias específicas de ácido nucleico de cada uno de los patógenos detectados, así como para el control del material de la plantilla. Estos cebadores están «anidados» o internalizados en los productos específicos de la primera etapa de la reacción múltiple, que potencia tanto la sensibilidad como la especificidad de las reacciones.

4. Análisis de fusión del ADN: después de la segunda etapa de la PCR, la temperatura aumenta lentamente y se controla la fluorescencia de cada depósito de la matriz, que se analiza para generar una curva de fusión. La temperatura a la que funde cada producto de la PCR específico (temperatura de fusión o Tm) es consistente y predecible, y el software evalúa automáticamente los datos de los depósitos replicados de cada ensayo para notificar los resultados. ${ }^{20}$

Rendimiento clínico. El rendimiento clínico de la PCR múltiplex se determinó durante un estudio multicéntrico realizado en cuatro centros de estudio geográficamente distintos de los Estados Unidos, entre mayo y septiembre de 2013. Un total de 1,578 especímenes de heces sobrantes del estudio prospectivo en medio de transporte Cary Blair se adquirieron para el estudio clínico; 22 de éstos fueron excluidos. Los motivos de exclusión más frecuentes fueron que no se completó un control externo válido el día del análisis, esto es, que el espécimen no se sembró en placas adecuadas en todos los medios de cultivo bacteriano requeridos por el método de referencia, o porque tenía más de cuatro días de antigüedad desde la fecha de recogida. El conjunto final de datos estaba compuesto por 1,556 especímenes.

La sensibilidad clínica o coincidencia de porcentaje positivo (PPA) se calculó como 100\% x (PV/[PV + NF]). Verdadero positivo (PV) indica que tanto la prueba molecular PCR, como el método de referencia/comparativo tuvieron un resultado positivo para un analito específico; y el falso negativo (NF) indica que el resultado del PCR fue negativo, mientras que el resultado del método comparativo fue positivo.

La especificidad o coincidencia de porcentaje negativo (NPA) se calculó como 100\% x (NV / [NV + PF]). El verdadero negativo (NV) indica que tanto la PCR como el método de referencia/comparativo tuvieron un resultado negativo, y un falso positivo (PF) indica que el resultado de la PCR fue positivo, mientras que el resultado del método comparativo fue negativo. Se calculó el intervalo de confianza exacto binomial bilateral de 95\%. Con índices de sensibilidad mínima de 94.5 al 100\% y especificidades mínimas de 97.1 al 100\%, dependiendo del agente bacteriano, viral o parasitario estudiado. ${ }^{20}$

Objetivos generales. La finalidad del siguiente estudio es describir la utilidad de una PCR múltiplex en comparación con otros métodos de diagnóstico aplicados en pacientes con sospecha de gastroenteritis infecciosa, evaluar los ajustes que se realizan en el tratamiento médico inicial, uso de antibióticos, reducción de complicaciones, días de estancia intrahospitalaria, prevalencia y datos epidemiológicos de los agentes causales reportados en nuestra población.

Universo. Se incluyeron pacientes con edad mínima de un mes y máxima de 93 años, promedio de 41 años, los cuales ingresaron con diagnóstico de gastroenteritis probablemente infecciosa, no hubo distinción de géne- 
ro y horario para su atención en un periodo de enero a junio de 2019. Selección aleatoria simple y muestreo no probabilístico por conveniencia con un total de 150 pacientes y un índice de confianza de 99\% por proporción.

Criterios de inclusión. Pacientes que ingresaron al Centro Médico ABC con datos clínicos compatibles con una gastroenteritis probablemente infecciosa, que requirieron hospitalización y a los que se les realizó una prueba de PCR múltiplex gastrointestinal. Además, que contaran con pruebas básicas de laboratorio para identificación de agentes causales de gastroenteritis como cultivo de heces, análisis coprológico, coproparasitoscópico, examen en fresco y pruebas antigénicas. Finalmente, que tuvieran expediente electrónico y seguimiento en la plataforma TIMSA completo.

Criterios de exclusión. Pacientes que no requirieron hospitalización, con prueba molecular PCR múltiplex invalidada o cancelada y los que no contaran con seguimiento y expediente incompleto

\section{MATERIAL Y MÉTODOS}

Todo paciente que haya ingresado al centro de cáncer, urgencias o cualquier otro servicio hospitalario y que contara con valoración médica inicial; se dio seguimiento a aquéllos que cumplieran con datos clínicos sugerentes de gastroenteritis, es decir, la presencia de evacuaciones disminuidas de consistencia y aumentadas en frecuencia, náusea, dolor abdominal, presencia o ausencia de sangre o moco en las evacuaciones y presencia o no de fiebre y vómito.

Se documentó con base en datos el género, número de expediente, edad, servicio inicial de ingreso y servicio final en caso de requerir mayor estancia hospitalaria, fecha de ingreso y egreso, días totales de hospitalización y días requeridos para el diagnóstico de gastroenteritis.

Se buscó de manera intencional aquellos factores de riesgo dentro de los antecedentes personales no patológicos que tuvieran relación directa y las comorbilidades dentro de los antecedentes personales patológicos que pudieran agravar la enfermedad.

Se dio continuidad al expediente electrónico y se registró el uso de antibiótico de manera empírica, plan de hidratación utilizado, estudios convencionales de identificación de microorganismos como examen en fresco, coprocultivo con antibiograma, coprológico, coproparasitoscópico, Rota-test y toxina de Clostridium dificile por ELISA. Se documentaron estudios básicos de laboratorio de función renal como creatinina sérica, sodio, potasio y cloro. Además, se utilizó el marcador de sepsis procalcitonina y la búsqueda intencionada de datos de respuesta infecciosa e inflamatoria sistémica con el uso de leucocitos totales.

Se incluyó a la base de datos una prueba de biología molecular PCR múltiplex panel gastrointestinal positiva o negativa, agente o agentes causales reportados de origen bacteriano, viral y parasitario.

Finalmente, se integró el diagnóstico inicial y final, escalamiento o desescalamiento farmacológico, recuperación o defunción del paciente y la educación para la aplicación de medidas preventivas en enfermedades infecciosas que requieren una cantidad mínima de inoculo para su contagio.

Aspectos éticos de la investigación. De acuerdo con el Reglamento de la Ley General de Salud en materia de investigación, este estudio se clasifica como sin riesgo. El protocolo se autorizó por el Departamento de Enseñanza e Investigación del Centro Médico ABC con un número de registro $\mathrm{TABC}-21-49$.

\section{RESULTADOS}

En un corte hasta el 30 de junio 2019 se incluyeron en total 150 pacientes que ingresaron a la institución con signos y síntomas sugerentes de gastroenteritis y que se dividieron en tres grupos. El primero de ellos representó $64 \%$ y corresponde a quienes salieron positivos para una prueba, ya sea por métodos tradicionales y una PCR múltiplex. El segundo grupo, con 19\%, aquéllos que no tuvieron un reporte de agente infeccioso. El tercero, con $7 \%$, los pacientes que se excluyeron al no contar con un expediente o seguimiento completo (Figura 2).

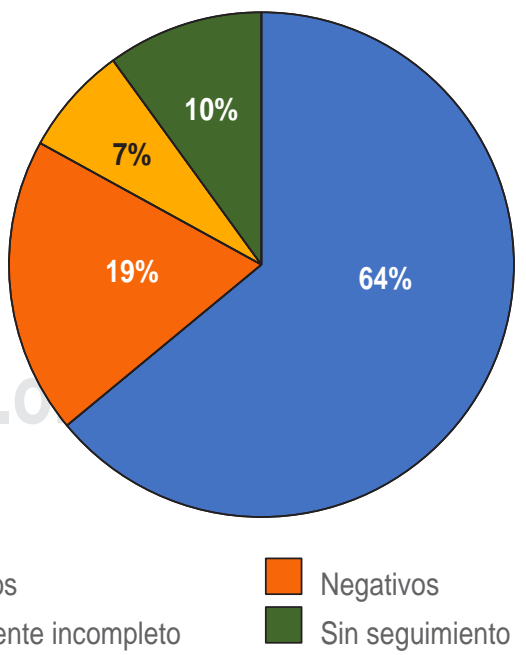

Figura 2: Resultados y población estudiada. 
Tabla 1: Principales comorbilidades.

\begin{tabular}{lcc} 
Comorbilidad & Casos & $\%$ \\
\hline Sedentarismo & 61 & 24.0 \\
Adulto mayor de 65 años & 41 & 16.0 \\
Estancia hospitalaria prolongada & 40 & 16.0 \\
Inmunosupresión & 28 & 11.0 \\
Viajes recientes & 18 & 7.0 \\
Malos hábitos dietéticos & 15 & 6.0 \\
Paciente menor de cinco años y & 12 & 5.0 \\
estancia en guarderías & & \\
Esquema de vacunación incompleto & 6 & 2.0 \\
Toxicomanías y zoonosis & 3 & 1.0 \\
Postración en cama y hacinamiento & 2 & 0.5 \\
Interrogados y negados & 13 & 5.0 \\
\hline
\end{tabular}

Tomando así un grupo final de 124 pacientes efectivos con un índice de confianza de 99\% por proporción.

De estos pacientes, $83 \%$ fueron adultos y $17 \%$ niños, de los cuales $54 \%$ fueron mujeres y $46 \%$ hombres, con una media de edad de 41 años, siendo la edad mínima de 1 mes y máxima de 93 años.

En cuanto al servicio de ingreso (118) 95\% fue por urgencias, (3) 2\% por la consulta externa de Oncología y el resto en ginecología (1), medicina crítica (1) y unidad de trasplantes (1). Los servicios que brindaron la atención fueron (41) 33\% medicina interna, (19) 15\% pediatría, cirugía general (16) y urgencias (16) con $13 \%$ respectivamente, oncología (12) 10\%, medicina crítica (9) 7\%, terapia intermedia (3) y unidad coronaria (3) con $2 \%$, respectivamente y el resto fueron hospitalizados en ginecología (1), terapia de pediatría (1), ortopedia (1), neonatología (1) y la unidad de trasplantes (1).

Las principales comorbilidades detectadas fueron (61) $24 \%$ con sedentarismo, adultos mayores de 65 años (41) $16 \%$ y estancia hospitalaria prolongada (40) $16 \%$, respectivamente, inmunosupresión (28) $11 \%$, viajes recientes a zonas endémicas (18) 7\%, malos hábitos dietéticos (15) $6 \%$, estancia en guarderías (12) y pacientes menores de cinco años (12) 5\%, respectivamente, esquema de vacunación incompleto (6) 2\%, toxicomanías (3) y zoonosis (3) $1 \%$, respectivamente y el resto por postración en cama (2) y estados de hacinamiento (2). Cabe resaltar que (13) $5 \%$ fueron interrogados y negados (Tabla 1 ).

En cuanto a la frecuencia de evacuaciones, se reporta un promedio de 9 al día, de acuerdo con el tipo de diarrea, la más común fue la inflamatoria con $89 \%$, persistente $7 \%$, disentérica $2 \%$ y $1 \%$ con incremento del gasto por colostomía.

En cuanto a los signos y síntomas, 52\% de los pacientes presentó vómito, $28 \%$ fiebre, $16 \%$ moco y $4 \%$ sangre.

Del total de pacientes se realizaron (145) $73 \%$ de pruebas convencionales y a (53) $27 \%$ no se le realizó ningún estudio para la detección de agentes infecciosos por este método.

El análisis coprológico tuvo (61) 31\% de solicitud con un índice de positividad de 54\%, detectando principalmente moco, sangre oculta en heces y la presencia de protozoo Blastocystis hominis de significado incierto.

El coprocultivo tuvo (40) $20 \%$ de solicitudes con un índice de positividad de $8 \%$ reportando Salmonella enterica en tres casos y la realización de antibiograma.

Para el análisis coproparasitoscópico se tuvo (22) 11\% de solicitud, reportando sólo un caso de Entamoeba histolytica como hallazgo con un índice de positividad de $5 \%$.

Dentro de las pruebas inmunológicas, el Rota-test (10) $5 \%$ tuvo una positividad de $20 \%$ y, finalmente, la detección de toxina para Clostridium difficile (12) 6\% no registró ninguna prueba positiva (Figura 3).

Los paraclínicos solicitados para evaluar el estado hidroelectrolítico, función renal y datos de respuesta inflamatoria sistémica y sepsis reportaron (186) 28\% hallazgos fuera del límite de referencia y (485) $72 \%$ sin alteraciones. La creatinina se solicitó en 114 pacientes con (15) 13\% de alteración; el sodio, potasio y cloro se cuantificaron en 117 pacientes, respectivamente, con (32) $27 \%$ sodio; (28) $24 \%$ potasio y (30) $26 \%$ cloro con alteraciones. Los reactantes de fase aguda y marcador de sepsis procalcitonina tuvo 85 solicitudes con (28) 33\% positivo (> $1 \mathrm{ng} / \mathrm{mL}$ ). Por su parte, la cuantificación de

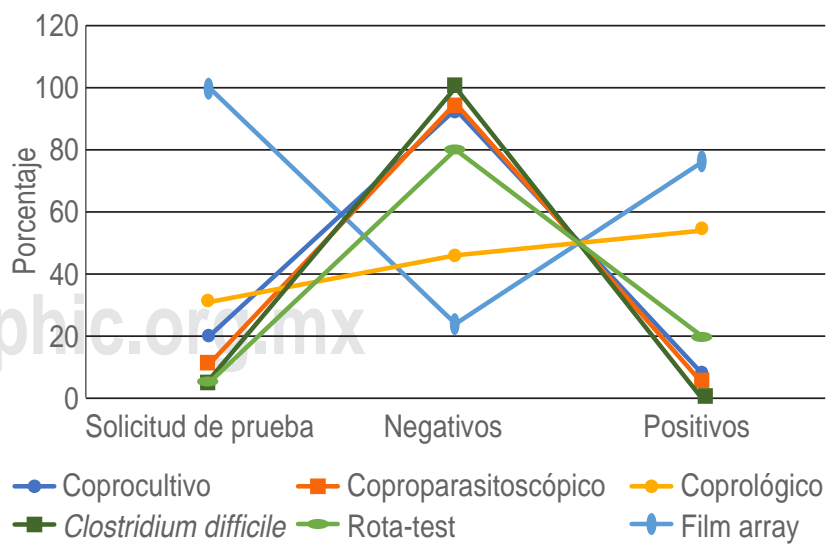

Figura 3: Estudios convencionales vs reacciones de la polimerasa en cadena múltiplex. 


\begin{tabular}{crcrc} 
& \multicolumn{3}{c}{ Tabla 2: Agentes infecciosos reportados. } \\
Bacterias & $\%$ & Virus & $\%$ & Parásitos \\
\hline E. coli enteropatógena (29) & 17 & Rotavirus (23) & 13.0 & Giardia lamblia (4) \\
E. coli enteroagregativa (28) & 16 & Norovirus (16) & 8.0 & Cyclospora cayetanensis (2) \\
E. coli enterotoxigénica (22) & 12 & Sapovirus (2) & 1.0 & Cryptosporidium (1) \\
Clostridium difficile A/B (17) & 9 & Adenovirus (2) & 1.0 & \\
E. coli enteroinvasiva (9) & 5 & Astrovirus (1) & 0.5 & \\
$\quad$ Salmonella (9) & 5 & & & \\
E. coli productora de toxina & 54 & & & \\
tipo Shiga (7) & 2 & & & \\
Plesiomonas shigelloides (3) & 1 & & & \\
Campylobacter (2) & 1 & & & \\
Vibrio cholerae (2) & & & & \\
\hline
\end{tabular}

leucocitos totales se solicitó en 121 pacientes con (53) $44 \%$ fuera del intervalo normal de referencia.

Dentro de los diagnósticos iniciales se reportan: gastroenteritis de probable origen infeccioso (GEPI) (110) 58\%, desequilibrio hidroelectrolítico (24) 13\%, choque séptico de origen a determinar (10) $5 \%$, toxicidad a quimioterapia (8) $4 \%$, dolor abdominal en estudio con (5) 3\%, intoxicación alimentaria (3), probable oclusión (3) o suboclusión intestinal y enfermedad diverticular (3) con $2 \%$, respectivamente, síndrome disentérico (2), probable sangrado de tubo digestivo (2), hernia umbilical encarcelada (2), hipotiroidismo (2), endometriosis (2) y pancreatitis aguda con $1 \%$, respectivamente, y otras como probable vólvulo duodenal (1), gastropatía erosiva (1), colecistitis crónica (1), íleo paralítico (1), gastroparesia (1), leiomiosarcoma (1), colección intraabdominal (1) y enfermedad injerto contra huésped (EICH) gastrointestinal (1) con 5\% restante.

La PCR múltiplex se solicitó en $100 \%$ de los pacientes, con un índice de positividad de (94) 76\%. Se detectó al menos un patógeno en (46) 49\%. En (23) 25\% casos se reportaron dos agentes, en (16) $17 \%$ casos la presencia de tres agentes, en (6) 6\% casos cuatro agentes, en (2) $2 \%$ de los casos cinco agentes y, finalmente, (1) $1 \%$ la presencia de seis agentes infecciosos simultáneos. Repitiendo el análisis a partir de cuatro agentes simultáneos para su validación.

Para los microorganismos de origen bacteriano (29) 17\% fue para Escherichia coli enteropatógena, 16\% Escherichia coli enteroagregativa (28), 12\% Escherichia coli enterotoxigénica (22), 9\% Clostridium difficile A/B (17), Escherichia coli enteroinvasiva (9) y Salmonella (9) con un 5\%, respectivamente, 5\% para Escherichia coli productora de toxina tipo shiga (7), 4\% Plesiomonas shigelloides (3) 2\%, Campylobacter (2) y Vibrio cholerae (2) con $1 \%$ restante.
Los virus entéricos reportados fueron rotavirus con un (23) $13 \%$, norovirus (16) con $8 \%$, sapovirus (2) y adenovirus (2) con $1 \%$, respectivamente, y astrovirus (1) con $0.5 \%$. En cuanto a los parásitos Giardia lamblia (4) representó $3 \%$, Cyclospora cayetanensis (2) 1\% y Cryptosporidium (1) el $0.5 \%$ (Tabla 2).

El diagnóstico final se reportó con (94) 69\% como gastroenteritis de origen infeccioso, $8 \%$ choque séptico de origen abdominal (11), 4\% adenocarcinoma de colon (5), $3 \%$ hipertiroidismo (4), diverticulitis (3) y oclusión intestinal (3) con $2 \%$, respectivamente; apendicitis aguda (2), intoxicación alimentaria (2), cirrosis hepática (2) y lupus eritematoso activo (2) con 1\% y otros como colección (1) colitis microscópica (1), adherencias gastrointestinales (1), gastritis erosiva (1), esofagitis crónica (1), infección por citomegalovirus (1), pancreatitis aguda (1) y síndrome de intestino irritable con $9 \%$ en conjunto.

Se inició tratamiento de rehidratación por diversas vías como medida inicial para esta patología; la vía parenteral representó 95\% del total de pacientes; la solución Hartmann $67 \%$, solución salina fisiológica con $19 \%$, solución Rubín Calcagno $6 \%$ y solución mixta $2 \%$. En cuanto a la vía oral, sólo fue usada en $5 \%$ del total de pacientes; el uso de fórmula láctea y electrolitos orales representó $2 \%$ y el seno materno $1 \%$.

En (89) $72 \%$ de los pacientes se inició terapia antimicrobiana empírica; de los cuales carbapenémicos (58) $30 \%$, cefalosporinas de tercera generación (33) 28\%, quinolonas (25) 20\%, glucopéptidos (7) en $6 \%$, antiparasitarios (4) 3\%, aminoglucósidos (2) y cefalosporinas de segunda generación (2) 2\%, macrólidos (1) 1\% y otros semisintéticos (7), aminopenicilinas (2) e inhibidores de THFR (1) con 5\% restante (Figura 4).

Posterior al resultado de PCR, se dirigió el tratamiento en (72) $63 \%$ de los pacientes. Los cambios en antibiotico- 
terapia fueron para cefalosporinas de tercera generación (24) $25 \%$, quinolonas (18) con $19 \%$, carbapenémicos (17) 18\%, glucopéptidos (16) 17\%, antiparasitarios (9) con 10\%, inhibidores de la THFR (3) 3\%, macrólidos (2) con $2 \%$, tetraciclinas (1), lipopéptidos (1), cefalosporinas de segunda generación (1) y semisintéticos (1) con 1\% y otros con 2\% (Figura 5).

La estancia intrahospitalaria fue dependiente de la patología de base, comorbilidad asociada, tratamiento implementado y complicaciones. El máximo fue de 48 días y un mínimo de un día, media total de seis días. Para el diagnóstico de gastroenteritis infecciosa mediante pruebas tradicionales se emplearon para el reporte máximo tres días y mínimo dos horas (0.08) día, con una media de 1.02 días. Para los tiempos de la PCR múltiplex, la emisión de resultado se hizo en 60 minutos (0.04) día en promedio. Los pacientes que no recibieron antibioticoterapia tuvieron una estancia intrahospitalaria de 3.2 días en promedio en comparación con los que sí recibieron de uno a tres antibióticos, con una media de 5.6 días. Finalmente, los pacientes que no tuvieron ninguna complicación tuvieron una estancia de un día y aquéllos con complicaciones en un periodo de hasta siete días.

El pronóstico del total de pacientes fue de (123) $99 \%$ recuperados y (1) 1\% de defunción por complicaciones de enfermedad de base. Se logró dar medidas preventivas, información epidemiológica y educación para la salud a $69 \%$ de los pacientes que presentaron algún microorganismo con alta capacidad de contagio con poca cantidad de inoculo como lo es Salmonella, Campylobacter, Vibrio cholerae, rotavirus, norovirus y sapovirus.

\section{DISCUSIÓN}

Con base en nuestro estudio se observó que la tasa de positividad para la prueba de PCR múltiplex es de $72 \%$, comparado con $54 \%$ del análisis coprológico, 20\% de Rota-test, $8 \%$ del coprocultivo, $5 \%$ de coproparasitoscópico y $0 \%$ de prueba para detección de toxina de Clostridium difficile.

El rotavirus tuvo una prevalencia en nuestro estudio de $18.5 \%$, el cual pudo compararse con una prueba de PCR múltiplex con una sensibilidad de 100\% y una especificidad de $99.2 \%$, VPP de $96.5 \%$ y VPN de $100 \%$ versus la prueba Rota-test, con una sensibilidad de $93.1 \%$ y especificidad de $95.8 \%$, VPP $83.39 \%$ y VPN de $98.38 \%$ estadísticamente significativo para PCR múltiplex.

Clostridium difficile tuvo una prevalencia de $13.7 \%$, el cual pudo compararse con una prueba de PCR múltiplex con una sensibilidad de $98.8 \%$, especificidad de $97.1 \%$, VPP de $84.3 \%$ y VPN de $99.7 \%$ versus la prueba inmunológica para detección de toxina $\mathrm{A} / \mathrm{B}$ de Clostridium difficile con una sensibilidad de $88.3 \%$, especificidad de $99.6 \%$,

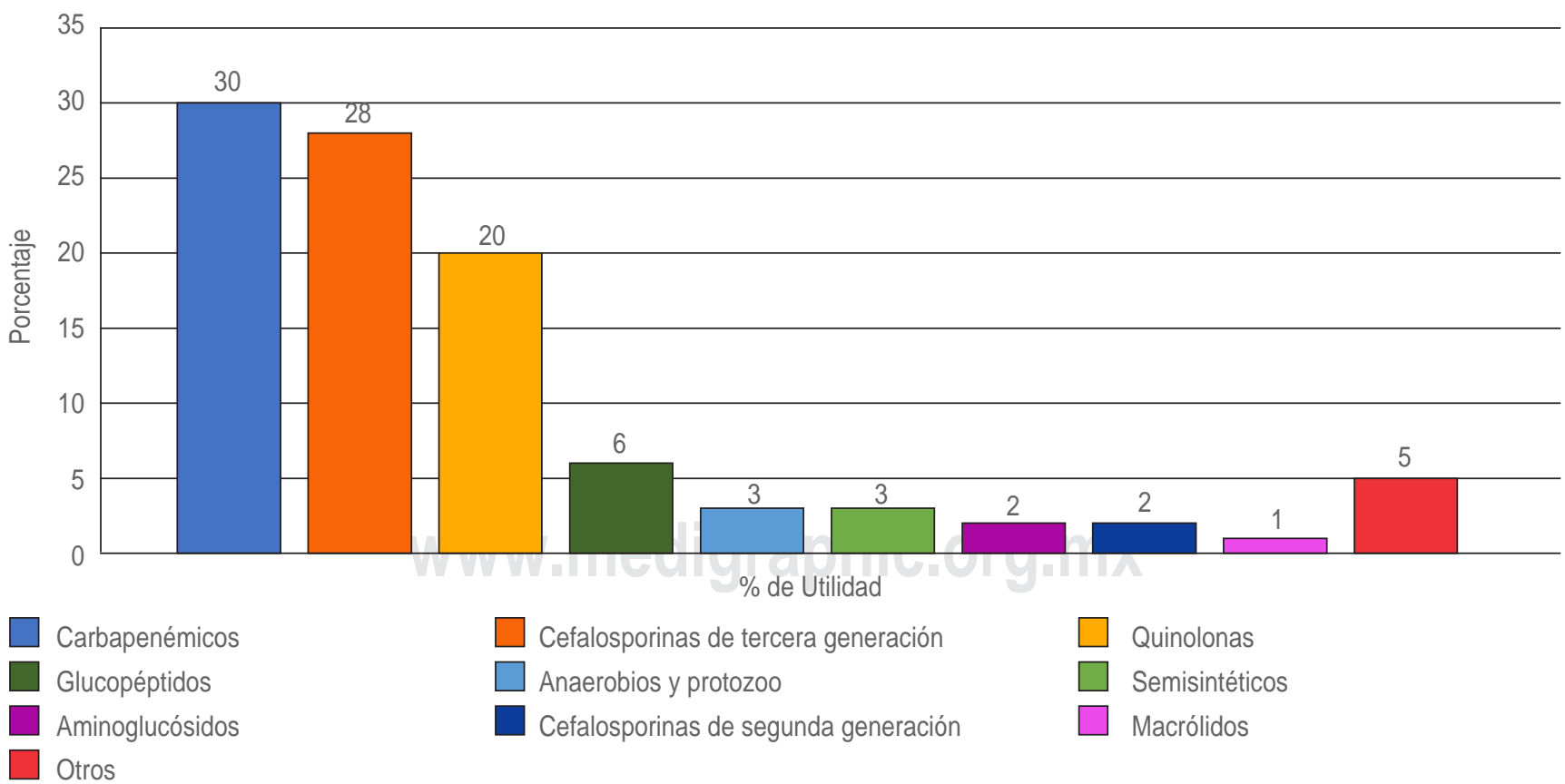

Figura 4: Uso de antibiótico empírico. 


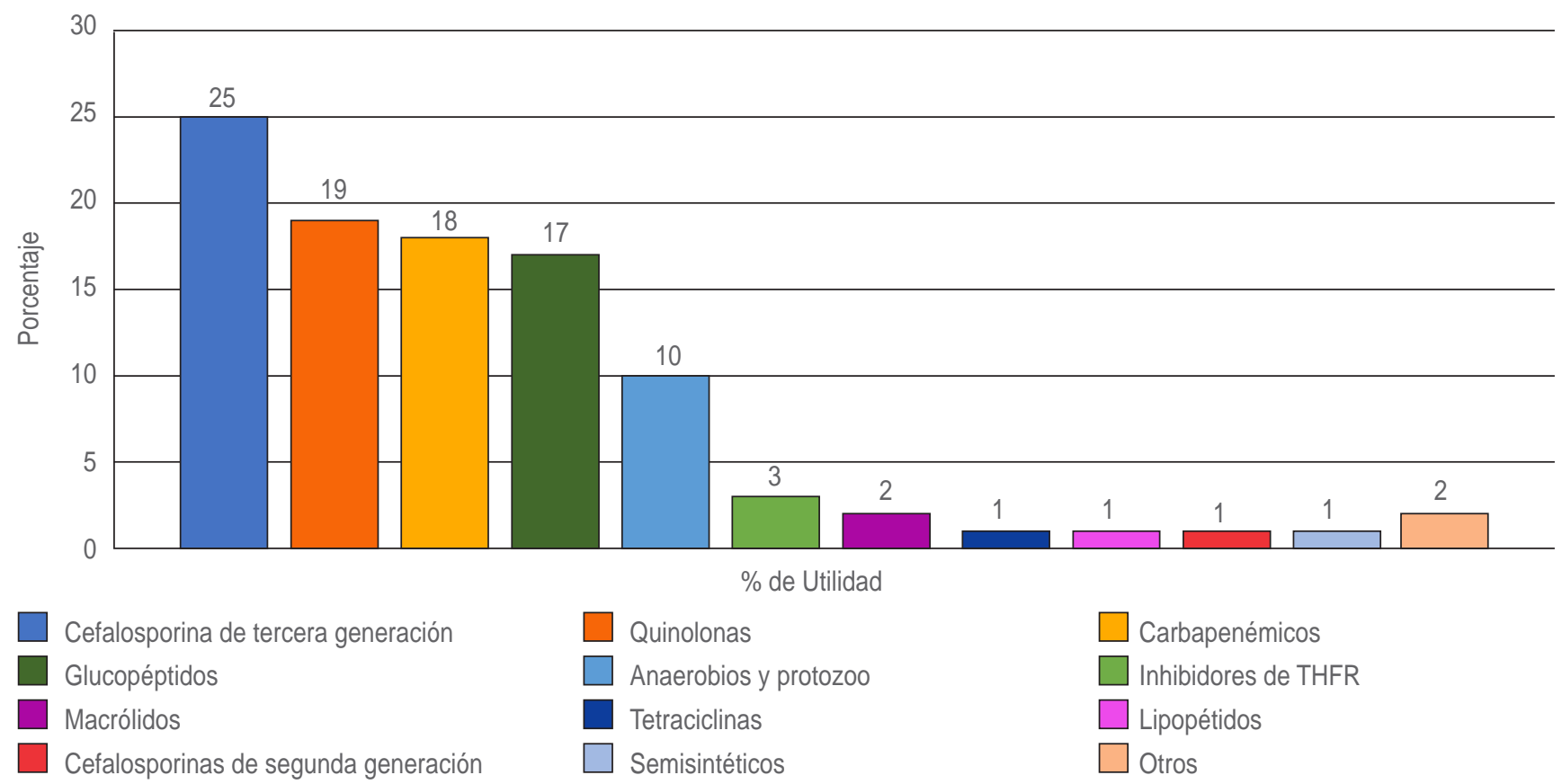

Figura 5: Modificación de antibiótico empírico.

\section{Tabla 3: Microorganismos detectados.}

\begin{tabular}{lr} 
Microorganismo & $\mathrm{n}$ (prevalencia) \\
\hline Escherichia coli enteropatógena (EPEC) & $29(23.3)$ \\
Escherichia coli enteroagregativa (EAEC) & $28(22.5)$ \\
Rotavirus A & $23(18.5)$ \\
Escherichia coli enterotoxigénica (ETEC) & $22(17.7)$ \\
Clostridium difficile & $17(13.7)$ \\
Norovirus & $16(12.9)$ \\
Escherichia coli enteroinvasiva (EIEC) & $9(7.2)$ \\
Salmonella & $9(7.2)$ \\
Escherichia coli productora de toxina tipo & $7(5.6)$ \\
Shiga (SLEC) & \\
Giardia lamblia & $4(3.2)$ \\
Plesiomonas shigelloides & $3(2.4)$ \\
Campylobacter & $2(1.6)$ \\
Vibrio cholerae & $2(1.6)$ \\
Sapovirus & $2(1.6)$ \\
Adenovirus & $2(1.6)$ \\
Cyclospora cayetanensis & $2(1.6)$ \\
Astrovirus & $1(0.8)$ \\
Cryptosporidium & $1(0.8)$ \\
Vibrio (parahaemolyticus y vulnificus) & $0(0.0)$ \\
Yersinia enterocolítica & $0(0.0)$ \\
Shigella & $0(0.0)$ \\
Entamoeba histolytica & $0(0.0)$ \\
\hline & \\
\hline
\end{tabular}

VPP 97.2\% y VPN 98.1\% estadísticamente significativo para PCR múltiplex.

Para el caso de Salmonella enterica se observó una prevalencia de $7.2 \%$, el cual pudo compararse con una prueba PCR múltiplex con una sensibilidad de 100\%, especificidad de $99.6 \%$, VPP de $94.9 \%$ y VPN de $100 \%$ versus el cultivo de heces en medio Salmonella/Shigella con una sensibilidad de $33 \%$, especificidad de $100 \%$, VPP de $100 \%$ y VPN de $95 \%$. En este caso coincide con un estudio hecho por Gary N. McAuliffe, donde el cultivo tiene un mayor VPP al ser más específico, comparado con la detección por métodos moleculares. ${ }^{21,22}$

Como hallazgo, el análisis coproparasitoscópico tuvo una observación directa del protozoo Entamoeba histolytica, mientras que la prueba molecular PCR múltiplex la marcó como negativa. En esta situación consideramos la posibilidad de un falso positivo operador dependiente durante el procesamiento de la muestra.

Los datos presentados nos hacen pensar que este método de diagnóstico además de ser rápido (menos de dos horas) podría servir como una herramienta de racionalización de antimicrobianos y la importancia que tiene como lo describe J. Antonio Praiz en su trabajo de enfermedades diarreicas agudas, que tengan congruencia clínica, diagnóstica y terapéutica. ${ }^{23}$

A diferencia de los reportes que la Secretaría de Salud y otros estudios donde el grupo de edad mayor- 
mente estudiado ha sido el de población pediátrica, por su relación alta con agentes infecciosos, sobre todo en menores de cinco años; en nuestro estudio se observa que la media de los pacientes fue de 41 años, siendo el grupo pediátrico sólo $17 \%$ de ellos; sin embargo, esto se puede explicar, ya que en nuestro hospital la mayor parte de los pacientes que ingresan son mayores de edad con patologías de base. El género no fue un factor predisponente para desarrollar gastroenteritis, pero sí fueron las comorbilidades principalmente el sedentarismo, adultos mayores de 65 años, estancias hospitalarias prolongadas y la inmunosupresión que se reporta en $67 \%$ en conjunto.

En cuanto a la prevalencia de microorganismos reportados, las bacterias del grupo Escherichia coli en todas sus variantes son las de mayor predominio de reporte hasta 54\%. Como lo describe Noemí Peña en su investigación, identificando un cambio claro en el patrón epidemiológico, sobre todo ETEC (Escherichia coli enterotoxigénica) más resistente al medioambiente y mayor capacidad de colonización. Sin embargo, EAEC es causante de diarrea persistente con prevalencia parecida a ETEC. EPEC se considera un patógeno emergente silenciosamente confuso y finalmente EIEC (Escherichia coli enteroinvasiva) está mayormente asociada con diarrea en niños menores de seis meses (Tabla 3). ${ }^{24}$

Llama mucho la atención que los pacientes que no recibieron antibiótico o que se les suspendió posterior a ello tuvieran una estancia menor, por lo que consideramos que la rehidratación junto con medicamentos de soporte son lo esencial en el tratamiento de estos pacientes.

Basados en estos resultados, nuestro estudio es uno de los primeros en realizar una investigación en población adulta y pediátrica dentro de una Institución de Tercer Nivel, tomando en cuenta no sólo la efectividad de la prueba para un diagnóstico certero y la información epidemiológica, sino también el impacto que tiene durante su uso en diversas áreas de hospitalización, su relación con otras enfermedades agudas y crónicas que comprometen el estado inmunológico de los pacientes; los cambios realizados en el manejo y tratamiento, además de la promoción y educación para la salud, permitiendo detectar microorganismos capaces de potenciales infecciones.

\section{CONCLUSIONES}

El panel PCR múltiplex FilmArray gastrointestinal mostró un alto rendimiento diagnóstico y una imagen más detallada del espectro de diversos patógenos involucrados en la gastroenteritis infecciosa. Además, con su uso y aplicación adecuada apoyó a la disminución de la estancia intrahospitalaria de los pacientes, reducción de complica- ciones, uso inadecuado de terapias antimicrobianas y la educación para la salud con implementación de medidas preventivas para enfermedades de diseminación rápida.

\section{LIMITACIONES}

Se necesitan realizar estudios de costos para identificar si existe una disminución significativa en la reducción de días de estancia intrahospitalaria, el uso de terapias, insumos y pruebas inadecuadas que permitan una mayor relación costo-beneficio para el tipo de paciente estudiado y su implementación en otras instituciones de salud.

\section{REFERENCIAS}

1. Guerrant RL, Van Gilder T. Practice guidelines for the management of infectious diarrhea. Clin Infect Dis. 2001; 32: 331-351.

2. World Health Organization: Diarrhoeal disease. Available in: https:// www.who.int/news-room/fact-sheets/detail/diarrhoeal-disease.

3. Aburto LI. Principales problemas de salud pública en México. Enfermedad diarreica. UNAM. 2018; pp. 159-178.

4. Instituto Nacional de Estadística y Geografía. Características de las defunciones registradas en México durante 2017. Enfermedades diarreicas agudas. 2017, pp. 30-31,

5. Gabor M. Effect of definitions of acute gastroenteritis episodes using symptom diaries in pediatric cohorts: a systematic review. Journal of Pediatric Gastroenterology and Nutrition. 2020; 3: e54.

6. Leyre L. Curso básico sobre patologías digestivas, diarrea. Elsevier. 2016; pp. 1-7.

7. Skyum F. Risk factors for contagious gastroenteritis in adult patients with diarrhoea in the emergency department - a prospective observational multicentre study. BMC Infect Dis. 2019; 19 (1): 1-11.

8. Elias N. Etiology and complications of acute gastroenteritis in hospitalized children. Ro J Pediatr. 2019; 68 (3): 171-175.

9. Rivera-Domínguez G. Pediatric Gastroenteritis. StatPearls Publishing. 2020. Available in: https://www.ncbi.nlm.nih.gov/books/ NBK499939/?report= printable.

10. Ramon RF. La fiebre. Rev Fac Med. 2014; 57 (4): 1-14.

11. Molina CJ. Deshidratación. Rehidratación oral y nuevas pautas de rehidratación parenteral. Pediatr Integral. 2019; 23 (2): 98-105.

12. Benéitez MA. Gastroenteritis aguda. Pediatr Integral. 2015; 19 (1): 51-57.

13. García-Lamberechts EJ. Factors predicting failure in empirical antibiotic treatment. An Sist Sanit Navar. 2017; 40 (1): 119-130.

14. Romero IL. Características clínicas, microbiológicas y hematológicas de los pacientes hospitalizados con diagnóstico de gastroenteritis aguda en el Hospital Star Medica Infantil Privado de enero a diciembre del 2010. 2011, pp. 9-68.

15. Montes M. Pruebas moleculares en el diagnóstico de la gastroenteritis aguda causada por virus. Enfermedades Infecciosas y Microbiología Clínica. 2008; 26 (S9): 81-85.

16. Vázquez EA. Panorama de la gastroenteritis infecciosa en México. Revista de Enfermedades Infecciosas en Pediatría. 2000; 14 (53): 42.

17. Albert de la Torre L. Gastroenteritis aguda. Guía ABE grupo patología infecciosa. Servicio de Pediatría, Hospital Doce de Octubre. 2019. Disponible en: https://guia-abe.es/temas-clinicos-gastroenteritisaguda.

18. Farfán $M$, Piamonte P. Panel FilmArray $G \mid \circledast$ en la detección de patógenos entéricos en deposiciones: experiencia preliminar. Rev Chil Infectol. 2016; 33 (1): 89-91. 
19. Machiels JD. Impact of the BioFire FilmArray gastrointestinal panel on patient care and infection control. PLoS ONE. 2020; 15 (2): 1-13.

20. Manual de instrucciones de FilmArray GI Panel CE=IVD. BioFire Diagnostics. 2014, pp. 12-36.

21. McAuliffe GN. Systematic application of multiplex PCR enhances the detection of bacteria, parasites, and viruses in stool samples. J Infect. 2013; 67: 122-129.

22. Praiz JA. Uso racional de los antibióticos en infecciones respiratorias agudas superiores y enfermedades diarreicas agudas y su congruencia clínica-diagnostica-terapéutica en la UMF 28 del IMSS. 2020, pp. 13-62.
23. Stockmann C. Detection of 23 gastrointestinal pathogens among children who present with diarrhea. J Pediatric Infect Dis Soc. 2017; 6 (3): 231-238.

24. Peña N. Investigación hemero-bibliográfica de aspectos más recientes de la producción de diarrea por los diferentes patotipos de Escherichia coli en México haciendo énfasis en ETEC y EHEC. 2006, pp. 15-132.

Conflicto de intereses: Los autores declaramos que no existe ningún conflicto de intereses para este estudio. 